\title{
A diagnostic approach to hemochromatosis
}

\author{
Anthony S Tavill MD ${ }^{1}$, Paul C Adams MD²
}

\begin{abstract}
AS Tavill, PC Adams. A diagnostic approach to hemochromatosis. Can J Gastroenterol 2006;20(8):535-540.

In the present clinical review, a diagnostic approach to hemochromatosis is discussed from the perspective of two clinicians with extensive experience in this area. The introduction of genetic testing and large-scale population screening studies have broadened our understanding of the clinical expression of disease and the utility of biochemical iron tests for the detection of disease and for the assessment of disease severity. Liver biopsy has become more of a prognostic test than a diagnostic test. The authors offer a stepwise, diagnostic algorithm based on current evidence-based data, that they regard as most cost-effective. An early diagnosis can lead to phlebotomy therapy to prevent the development of cirrhosis.
\end{abstract}

Approche diagnostique de l'hémochromatose

\begin{abstract}
Dans cette revue, deux médecins qui connaissent bien l'hémochromatose présentent leur point de vue sur une approche diagnostique pour cette entité clinique. L'avènement des tests génétiques et les études de population à grande échelle ont permis d'approfondir les connaissances sur l'expression clinique de la maladie et ont confirmé l'utilité des analyses biochimiques et des dosages du fer pour dépister la maladie et en évaluer la gravité. La biopsie hépatique est désormais davantage considérée comme un test pronostique que comme une épreuve diagnostique. Les auteurs proposent un algorithme diagnostique en étapes qui se fonde sur des données factuelles récentes; ils estiment que cet algorithme permet un meilleur rapport coût-efficacité puisqu'un diagnostic précoce peut mener à un traitement par phlébotomie et prévenir la cirrhose.
\end{abstract}

Key Words: Hemochromatosis; HFE; Iron overload

$\mathrm{H}$ ereditary hemochromatosis $(\mathrm{HH})$ is often referred to as the ideal disease for screening, because diagnostic tests and treatment are readily available and the genetic prevalence is high (one in 227) in Caucasian populations (1). However, large-scale population screening studies have identified many asymptomatic patients and control populations without HFE mutations who often have similar symptoms (1-3). The natural history of untreated disease has not been clearly established and likely will not be forthcoming in clinical trials. In the present review, we summarize current concepts on screening for hemochromatosis.

\section{DEFINITION OF IRON OVERLOAD STATES}

The recognition of iron overload conditions represents a potentially important public health initiative, because in many circumstances, the consequences of iron-induced organ damage are preventable with timely diagnosis and therapeutic intervention. Although there are many causes of iron overload, the majority of such cases in the North American population are the result of a well-identified genetic disorder termed 'hereditary hemochromatosis', which is transmitted as an autosomal recessive condition resulting from a mutation of a gene (HFE) located on the short arm of chromosome 6 (4). The predominant mutation $(\mathrm{C} 282 \mathrm{Y})$ is the result of a $\mathrm{G}$ to $\mathrm{A}$ missense substitution resulting in the replacement of tyrosine for cysteine at the 282 amino acid position of the protein product of the HFE gene. This mutation genetically defines the condition of $\mathrm{HH}$. When fully expressed, the phenotypic consequences of the homozygous C282Y mutation is the progressive accumulation of parenchymal iron in a number of body organs, predominantly the liver, pancreas, heart, joints and endocrine tissue, with ultimate evidence of structural and functional damage to those organs (5). $\mathrm{HH}$ is somewhat unique among genetic conditions in that it is only in late or middle age that life-threatening consequences of iron accumulation in the tissues may become apparent by development of liver damage (fibrosis or cirrhosis), diabetes mellitus and cardiomyopathy.

It is this latent period between the inheritance of the genetic predisposition and the development of serious, symptomatic, phenotypic consequences that offers the challenge and opportunity for early diagnosis and treatment. This challenge for early diagnosis is further emphasized by the very high prevalence of the homozygous genetic mutation (C282Y) in the Caucasian population in North America (one in 227) (1), and the accessibility of phenotypic and genotypic laboratory markers to primary care physicians. Despite these encouraging guides to management, there remain controversial aspects of the natural history of $\mathrm{HH}$ that give valid grounds for some questioning of the application of these diagnostic techniques to a general and otherwise healthy population. It is only with the availability of unselected population studies that the previously held notion of $100 \%$ penetrance of the homozygous mutation has come under revised scrutiny $(1,2,6)$. It is now recognized that up to $50 \%$ of C282Y homozygotes may not have significant, clinically relevant iron overload even by middle age, thereby stimulating re-evaluation of the cost-effectiveness of screening using a combination of phenotypic indirect iron markers and gene

${ }^{1}$ Case Western Reserve School of Medicine and Cleveland Clinic Foundation, Cleveland, Ohio, USA; ${ }^{2}$ University Hospital, University of Western Ontario, London, Ontario

Correspondence: Dr Paul C Adams, University Hospital, 339 Windermere Road, London, Ontario N6A 5A5.

Telephone 519-685-8500 ext 35375, fax 519-663-3549, e-mail padams@uwo.ca

Received for publication October 26, 2005. Accepted December 20, 2005 


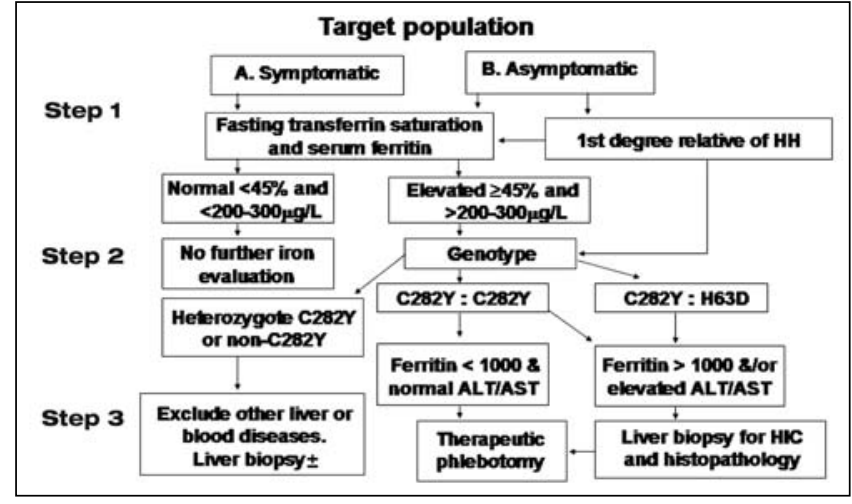

Figure 1) Diagnostic algorithm for the investigation of patients for hemochromatosis (12). ALT Alanine aminotransferase; AST Aspartate aminotransferase; HH Hereditary hemochromatosis; HIC Hepatic iron concentration

mutational analysis $(7,8)$. There are fewer doubts and more evidence in support of family screening, and in the promotion of iron overload evaluation in offices and clinics that take care of patients with liver disease, diabetes mellitus, otherwise unexplained cardiac disease, arthropathies and male sexual dysfunction (9).

\section{CLASSIFICATION OF IRON OVERLOAD STATES}

While the scope of this background discussion includes the evaluation of all iron overload conditions, it focuses primarily on HH. Most causes of HH are HFE-related. However, recently, there have been a small number of familial cases of $\mathrm{HH}$ that have met all the phenotypic criteria for the diagnosis, but in whom no mutation of the HFE gene could be detected $(10,11)$. Information on alternative gene mutations is accumulating from isolated case studies that may explain an unknown proportion of the $10 \%$ of non-HFE mutations in families with classical $\mathrm{HH}$. The diagnostic algorithm for $\mathrm{HH}$, adopted by the American Association for the Study of Liver Diseases and its sister gastroenterology societies, provides a pathway for HFErelated $\mathrm{HH}$, non-HFE-related $\mathrm{HH}$, and for various forms of secondary iron overload (Figure 1) (12).

\section{CLINICAL FEATURES OF HH}

The classical features of $\mathrm{HH}$ first described at the end of the 19th century in Europe, and further consolidated in the monograph published by Sheldon in 1935 (13), represent the fully developed syndrome of $\mathrm{HH}$, with advanced end-organ damage typified by cirrhosis, diabetes mellitus, skin pigmentation, cardiomyopathy, hypogonadism and arthropathy. Studies of large pedigrees of symptomatic probands had previously indicated that the majority of such cases presented with clinical features of the above complications, and on further evaluation, most were found to have established cirrhosis and diabetes $(14,15)$. Because the awareness of the condition has evolved, and with the discovery of asymptomatic individuals with $\mathrm{HH}$, a far greater percentage of patients are younger, free of cirrhosis and diabetes, and have a much improved prognosis for survival (15-17). These studies have encompassed longitudinal evaluation of probands and homozygous family members over the last five decades of the 20th century, and have indicated that the discovery and treatment of an $\mathrm{HH}$ individual before the development of these complications is associated with a normal life expectancy (15).
At least $60 \%$ of all $\mathrm{HH}$ deaths are related to complications of iron overload, and three-quarters of these can be directly ascribed to complications of liver disease, either liver failure associated with cirrhosis or primary hepatocellular cancer that develops on the background of cirrhosis $(15,18)$. Cirrhosis, once developed, is rarely reversible, and primary hepatocellular cancer remains a risk in $\mathrm{HH}$ with associated cirrhosis, regardless of the successful removal of iron by phlebotomy therapy. Complications of diabetes mellitus are the second most common cause of death in $\mathrm{HH}$ (15). While there are data to suggest that the control of diabetes mellitus in the insulindependent diabetic is improved by adequate phlebotomy, there are no data available to demonstrate reduction of diabetesrelated deaths once the disease is established. By analogy, with secondary iron overload associated with dyserythropoietic anemias, there is a presumption that de-ironing therapy may also serve to prevent the potentially life-threatening cardiomyopathy of iron overload. However, this is not an evidencebased conclusion in HH. Similarly, there are no data to support the notion that early diagnosis and treatment of $\mathrm{HH}$ prevents the occurrence of less life-threatening but quality-of-lifeaffecting complications such as arthropathy and hypogonadism in the male patient. Arthritis is usually not improved by iron depletion therapy. Several large pedigree studies, spanning 40 to 50 years, indicated that the overall prevalence of cirrhosis and/or diabetes was approximately $70 \%(15,16)$. However, these studies also indicated that the occurrence of these complications was very much lower in individuals discovered by pedigree analysis; in cases of $\mathrm{HH}$ diagnosed within the past decade, the overall frequency of specific symptoms and complications such as cirrhosis and diabetes fell considerably. In population screening studies, the prevalence of cirrhosis may be as low as $1 \%$ to $5 \%(19,20)$, and diabetes has not been clearly established to be a unique symptom of hemochromatosis because the prevalence in control populations appears to be similar $(1,2)$. There are data to show that if the diagnosis is based on mutation analysis of relatively unselected populations, only a minority of $\mathrm{C} 282 \mathrm{Y}$ homozygotes are symptomatic and, on further evaluation, very few show evidence of chronic liver disease or diabetes unless there are additional risk factors such as alcohol abuse, hepatitis C or obesity $(21,22)$. It is unclear whether this 'changing scene' (16) relates to differences in the rate of accumulation of iron among genetic homozygotes or to previously unrecognized differences in the susceptibility of different families to the toxic effects of storage iron. Previous evidence suggested that clinically, $\mathrm{HH}$ evolved in progressive stages: stage 1 (zero to 20 years of age, $0 \mathrm{~g}$ to $5 \mathrm{~g}$ storage iron; stage 2 (approximately 20 to 40 years of age, $5 \mathrm{~g}$ to $20 \mathrm{~g}$ storage iron); and stage 3 (usually older than 40 years of age, in excess of $20 \mathrm{~g}$ storage iron) $(15,23,24)$. Women usually manifest clinical features of iron overload five to 10 years later than men, probably because of the physiological losses of iron during the reproductive period of their lives. It was the notion of the progressive, age-related accumulation of storage iron that led to the concept of the hepatic iron index (HII) and the critical hepatic iron level associated with fibrosis and cirrhosis $(25,26)$. It is now recognized that there are a small minority of genetic homozygotes who do not exhibit a rate of accumulation of iron (HII) that had previously been regarded as diagnostic for $\mathrm{HH}$ (greater than $1.9 \mu \mathrm{mol} / \mathrm{g} /$ year), and that other types of iron overload may manifest with a HII greater than $1.9 \mu \mathrm{mol} / \mathrm{g} /$ year $(23)$. 


\section{DIAGNOSTIC ALGORITHM FOR HH}

The diagnosis of $\mathrm{HH}$ may be sought in symptomatic patients with clinical features compatible with $\mathrm{HH}$; asymptomatic firstdegree relatives of patients with previously diagnosed $\mathrm{HH}$; asymptomatic patients being investigated for other conditions in whom there is suspicion of $\mathrm{HH}$ because of serendipitous findings of abnormal liver enzymes or elevated iron markers, or who are suspected during the course of evaluation of other associated conditions such as diabetes mellitus, atypical arthropathy or cardiomyopathy; and the general population. It is generally agreed that the minimum criteria for the diagnosis of $\mathrm{HH}$ are increased iron stores and/or C282Y/C282Y or C282Y/H63D HFE gene mutations. Although it is controversial whether a gene mutational analysis in itself may define $\mathrm{HH}$, the ultimate necessity for treatment is defined by the assessment of the extent of iron loading.

Assessment of the diagnostic accuracy of phenotypic screening methods have been derived both from unselected populations (27) and from families of detected probands homozygous for the C282Y mutation (28). There is a concern in family-based studies that elevated iron tests were part of the diagnostic criteria, and this introduces a diagnostic incorporation bias (29). On the basis of these data and cost-effectiveness analyses, a diagnostic algorithm has been developed and adopted by gastroenterological societies for the evaluation of patients suspected of having $\mathrm{HH}$ (12).

\section{Step 1: Blood studies}

Because it is now generally agreed that the definition of hemochromatosis is based first and foremost on phenotypic evidence of iron overload, with secondary confirmation that the condition can be further defined as $\mathrm{HH}$ by genotypic analysis, the initial approach to diagnosis is by indirect markers of iron stores, namely, transferrin saturation (TS), unsaturated iron binding capacity (UIBC) and serum ferritin. TS is calculated from the ratio of serum iron to total iron binding capacity. In some laboratories, the ratio of serum iron to total iron binding capacity is calculated from the sum of the serum iron and the UIBC; in others, it is calculated from the transferrin concentration in serum. Ideally, TS should be measured after an overnight fast to avoid circadian and postprandial variations. The use of a nonfasting sample increases the falsepositive rate (30). The sensitivity, specificity and positive predictive value depend on the population examined. A value exceeding $45 \%$ for TS may be the appropriate cut-off value to maximize both positive and negative predictive accuracy in the detection of iron overload $(1,31)$. There have been population studies that have shown significantly lower sensitivity for TS greater than $50 \%$ (2), and this is likely related to the high prevalence of nonexpressing C282Y homozygotes (32). UIBC has recently been shown to have a similar, or slightly better, performance than TS in detecting C282Y homozygotes, at a lower cost. A UIBC below $26 \mu \mathrm{mol} / \mathrm{L}$ had a sensitivity of $90 \%$, a specificity of $90 \%$ and a positive predictive value of $2.2 \%$ for detecting C282Y homozygotes (27). It is well known that men have a greater expression of biochemical iron abnormalities and clinical expression of symptoms in hemochromatosis.

There have been several studies of families with $\mathrm{HH}$ demonstrating that the serum ferritin concentration provides valuable correlation with the size of body iron stores $(28,33)$ (Table 1). Because iron stores accumulate progressively
TABLE 1

Prevalence of elevated ferritin in C282Y homozygotes identified in screening studies

\begin{tabular}{|c|c|c|c|c|}
\hline \multirow[b]{2}{*}{$\begin{array}{l}\text { Population } \\
\text { sample } \\
\text { (reference) }\end{array}$} & \multirow[b]{2}{*}{$\begin{array}{l}\text { Number } \\
\text { screened }\end{array}$} & \multicolumn{3}{|c|}{ C282Y homozygotes } \\
\hline & & Prevalence & $\begin{array}{l}\text { Male, ferritin } \\
>300 \mu \mathrm{g} / \mathrm{L} \\
\text { or } 250 \mu \mathrm{g} / \mathrm{L}^{*}\end{array}$ & $\begin{array}{c}\text { Female, } \\
\text { ferritin } \\
>200 \mu \mathrm{g} / \mathrm{L}^{*}\end{array}$ \\
\hline Electoral roll (56) & 1064 & 1 in 213 & $1 / 1(100 \%)$ & $2 / 4(50 \%)$ \\
\hline $\begin{array}{c}\text { Ambulatory } \\
\text { care (57) }\end{array}$ & 1653 & 1 in 276 & $1 / 1(100 \%)$ & $2 / 5(40 \%)$ \\
\hline $\begin{array}{l}\text { Epidemiology } \\
\text { survey (6) }\end{array}$ & 3011 & 1 in 188 & $5 / 5(100 \%)$ & $3 / 7(43 \%)$ \\
\hline $\begin{array}{c}\text { Ambulatory } \\
\text { care (2) }\end{array}$ & 41,038 & 1 in 271 & $55 / 72(76 \%)^{*}$ & $43 / 79(54 \%)$ \\
\hline $\begin{array}{r}\text { Ambulatory } \\
\text { care }(19)\end{array}$ & 65,238 & 1 in 220 & $90 \%{ }^{\dagger}$ & $60 \% *$ \\
\hline $\begin{array}{l}\text { Ambulatory } \\
\text { care (HEIRS) (1) }\end{array}$ & ) & $\begin{array}{c}1 \text { in } 227 \\
\text { in Caucasians }\end{array}$ & $88 \%$ & $57 \%$ \\
\hline
\end{tabular}

${ }^{*}$ Ferritin $>250 \mu \mathrm{g} / \mathrm{L}$ was the lower limit for males in reference $2 ;$ ' In this large study, genetic testing was only done in cases with an elevated transferrin saturation. The lower expression in women was estimated from observed versus expected prevalence of iron overload. HEIRS Hemochromatosis and Iron Overload Screening study

through life in the majority of $\mathrm{HH}$ patients, it is not surprising that there have been a number of reports of young homozygotes with normal serum ferritin and elevated TS level. Nevertheless, in most circumstances, serum ferritin provides additional confirmation of the significance of elevated TS in homozygotes. A serum ferritin level in the normal range, in combination with a TS level less than $45 \%$, has a negative predictive value of $97 \%$ for excluding iron overload (28). In a large study (2) correlating phenotypic and genotypic markers in a primary care population in California $(41,038$ persons screened), serum ferritin greater than $250 \mu \mathrm{g} / \mathrm{L}$ in males and greater than $200 \mu \mathrm{g} / \mathrm{L}$ in females was positive in $76 \%$ and $54 \%$, respectively, of C282Y homozygotes.

It is recognized that a variety of disease conditions unrelated to iron overload may cause a nonspecific rise in serum ferritin, and for this reason, a raised serum ferritin in the absence of an elevated TS may be nonspecific. However, iron overload may be present in a patient with an elevated ferritin level and a normal TS level, particularly in non-HFE-related iron overload (10). Therefore, a significant elevation in serum ferritin (greater than $1000 \mu \mathrm{g} / \mathrm{L}$ ) with a normal TS and no obvious explanation may require a liver biopsy to determine whether iron overload is present.

Finally, the serum ferritin has an additional value as a predictor of fibrosis or cirrhosis in confirmed HH. Several studies have now demonstrated that a level of serum ferritin less than $1000 \mu \mathrm{g} / \mathrm{L}$ is an accurate predictor of the absence of cirrhosis, independent of the duration of the disease (34-36).

\section{Step 2: Mutation analysis for $\mathrm{C} 282 \mathrm{Y}$ and $\mathrm{H} 63 \mathrm{D}$}

Because phenotypic expression is the sine qua non of the need for treatment of iron overload, a fasting TS level less than $45 \%$ and a normal serum ferritin level in a patient or screened individual would require no further evaluation. Elevation of these iron markers would be followed by genotypic testing. This consists of the determination of the HFE gene mutations C282Y and H63D that account for greater than $90 \%$ of cases of phenotypic HH. The studies that yielded these figures were summarized at a National Institutes of Health conference on $\mathrm{HH}$ 
(37). In Canada, the genetic test is provided free of charge by provincial DNA diagnostic laboratories when ordered by a physician. C282Y homozygotes or C282Y:H63D compound heterozygotes who have no additional risk factors (viral hepatitis, alcohol abuse) or indications of significant hepatic damage, who have indirect markers in the blood of iron overload, may be offered therapeutic phlebotomy without further evaluation. There are now a number of studies that indicate that individuals younger than 40 years of age with no hepatomegaly, a normal alanine aminotransferase level without a history of viral hepatitis or alcohol abuse, and a serum ferritin level less than $1000 \mu \mathrm{g} / \mathrm{L}$, have a minimal risk for fibrosis or cirrhosis of the liver (34-36).

There have been rare cases of iron overload associated with genetic mutations in newly identified, iron-related genes such as ferroportin, hemojuvelin, hepcidin, ceruloplasmin and transferrin receptor $2(10,11,38)$. The prevalence of these mutations has not been established in population studies. Genetic testing for these conditions is far more complex than for HFE mutations because multiple different mutations occur over large regions of the genes. Because these are rare and the testing is complex, it seems unlikely that commercial testing will become available for these conditions.

With regard to evaluation of first-degree relatives of a known proband, it may be argued that mutation analysis should be carried out on all those older than 20 years of age, so that appropriate monitoring of C282Y homozygotes or C282Y:H63D compound heterozygotes using phenotypic indirect markers may be carried out at regular intervals. A cost-effectiveness analysis suggested that the determination of the genetic risks for children of a proband may be best achieved by mutation analysis of the spouse (39); however, nonpaternity is a risk with this approach.

\section{Step 3: Phlebotomy therapy with or without a liver biopsy} On the basis of the evidence provided above, we feel that there are indications for liver biopsy under certain specific circumstances:

\section{- C282Y homozygotes or C282Y:H63D compound} heterozygotes with hepatomegaly, abnormal liver tests, associated risk factors for liver disease or a serum ferritin level greater than $1000 \mu \mathrm{g} / \mathrm{L}$;

- C282Y heterozygotes whose indirect iron markers suggest the possibility of extreme iron overload, eg, serum ferritin level greater than $1000 \mu \mathrm{g} / \mathrm{L}$; and

- non-HFE-related iron overload based on an elevated serum ferritin level (greater than $1000 \mu \mathrm{g} / \mathrm{L}$ ).

Under the above circumstances, liver biopsy provides useful documentation of the presence of cirrhosis, which in itself carries risks for morbidity and mortality that require surveillance and treatment (15). It also provides tissue for the histopathological evaluation and biochemical measurement of iron stores.

It had been suggested in earlier studies that most patients with homozygous $\mathrm{HH}$ steadily accumulate iron throughout life and carry a risk of fibrosis or cirrhosis when the level of iron concentration exceeds $300 \mu \mathrm{mol} / \mathrm{g}(22,000 \mu \mathrm{g} / \mathrm{g})$ dry weight $(20-22)$. However, it is now recognized that there are individuals with homozygous $\mathrm{HH}$ who develop fibrosis earlier in the face of other risk factors, and that there are other individuals who exceed this 'threshold' value without developing cirrhosis (40). Furthermore, the concept of the HII, which is a measure of the rate of iron accumulation, is now recognized to be a less stringent criterion for $\mathrm{HH}$. It is therefore argued that knowledge of the presence of cirrhosis may be used as a guideline for continued monitoring of an $\mathrm{HH}$ patient in the office or clinic for the pre-emptive diagnosis and treatment of such complications.

If a liver biopsy is regarded as unnecessary by the absence of all the above criteria, the ultimate test of total body iron stores is the amount of iron removed by phlebotomy. Patients with symptomatic $\mathrm{HH}$ usually require removal of $5 \mathrm{~g}$ to $20 \mathrm{~g}$ of iron before becoming iron depleted. Those diagnosed in the presymptomatic stage usually are iron depleted much earlier (removal of $3 \mathrm{~g}$ to $5 \mathrm{~g}$ ).

To summarize this end point of the diagnostic algorithm, evidence-based data suggest that liver biopsy is valuable as a prognostic indicator in $\mathrm{HH}$ but also provides a guideline for subsequent appropriate clinical care when cirrhosis is detected. However, it should be recognized that nongastroenterologists may have strong opinions against liver biopsy, and that ultimately, this is an optional procedure to be discussed with the patient. If cirrhosis is suspected after clinical evaluation, follow-up guidelines for a cirrhotic patient would be recommended. These include a consideration of elective endoscopy to assess for esophageal varices, and an abdominal ultrasound and alpha-fetoprotein to screen for hepatocellular carcinoma.

\section{SCREENING OF THE GENERAL POPULATION}

In considering the evidence required to make a decision as to whether to screen the general population for $\mathrm{HH}$, it is important to assess phenotypic-genotypic correlations - in particular, the degree to which individuals with predisposing mutations of the HFE gene may manifest abnormal iron markers and may go on to develop clinical features of iron overload.

Genetic testing has been a major advance in the diagnosis of hemochromatosis, but it has also identified typical C282Y homozygotes for the HFE mutation without iron overload. This is most apparent in population screening studies, but may also occur during a pedigree investigation. In regard to $\mathrm{C} 282 \mathrm{Y}$ homozygotes, a spectrum has been identified that includes the following three categories of patients.

\section{C282Y homozygotes with normal TS and ferritin levels}

It is uncertain at the present time what percentage of these patients may develop iron overload in the future. Most cases have been described in adults, and it has only rarely been reported that a 'nonexpressing' homozygote has developed abnormal iron tests. The cost of follow-up of these patients, who may never develop iron overload, is not insignificant, because this may represent up to $50 \%$ of $\mathrm{C} 282 \mathrm{Y}$ homozygotes $(32,41)$.

There have been several studies that have genotyped populations many years after initiating follow-up for other diseases $(42,43)$, and these studies have demonstrated that not all C282Y homozygotes have progressive iron overload. The Copenhagen Heart Study (43) monitored 23 C282Y homozygotes for up to 25 years, and although iron tests increased slightly, overt disease was not apparent. However, even in patients with significant iron overload, hepatic fibrosis is often a silent condition until the complications of cirrhosis develop.

C282Y homozygotes with an elevated TS and/or ferritin level This is a group of patients that often comes to medical attention for some other medical reason. They are often asymptomatic or have nonspecific symptoms such as fatigue, 
for which attribution to hemochromatosis is uncertain. In some of these, an elevated TS level can be attributed to a low transferrin level as a feature of some other chronic disease. However, the natural history in these mildly affected cases without treatment has not been well established, and historical data have identified untreated cases in which the iron tests were not progressively rising (44). Most new cases fall into this group and should not develop organ damage with appropriate treatment.

\section{C282Y homozygotes with significant iron overload and organ damage}

These patients have dominated studies from tertiary referral centres, and thus, the morbidity of hemochromatosis may have been overestimated. Serum ferritin correlates best with cirrhosis of the liver. Cirrhosis can be predicted in C282Y homozygotes by a clinical index using a serum ferritin level greater than $1000 \mu \mathrm{g} / \mathrm{L}$, a platelet count of less than $200 \times 10^{9} / \mathrm{L}$ and an aspartate aminotransferase level greater than $40 \mathrm{U} / \mathrm{L}$ (35). Diabetes is often present in the cirrhotic patients.

An important issue is whether population screening studies are detecting patients with significant disease. In a large screening study (19), 65,238 Norwegians were screened using TS twice, and cases were confirmed by genetic testing and/or liver biopsy. There were 147 liver biopsies performed; four men and none of the women had cirrhosis. The Hemochromatosis and Iron Overload Screening (HEIRS) study has demonstrated a minimum risk of $0.66 \%$ that $\mathrm{C} 282 \mathrm{Y}$ homozygotes have liver fibrosis (45). An Australian study of 3011 persons (6) led to liver biopsies in six cases, resulting in one patient with cirrhosis and two with fibrosis. Another screening study (2) of 41,038 persons from San Diego, California, USA, suggested that the prevalence of significant, life-threatening complications of hemochromatosis in $\mathrm{C} 282 \mathrm{Y}$ homozygotes may be as low as $1 \%$. In this study, some patients had suspected liver dysfunction but liver biopsies were not performed. The inclusion of a control group in this study highlighted the difficulty of attribution of symptoms in hemochromatosis, because a significant proportion of the general population have fatigue, arthralgias and diabetes. This discrepancy between the morbidity in referred patients and the lack of morbidity in screened patients is not unique to hemochromatosis. A neonatal screening study (46) performed in France emphasized the detection of $\mathrm{C} 282 \mathrm{Y}$ homozygotes in the families of the newborns (reverse cascade screening). The use of genetic testing for late- (or absent) onset disease remains an ethical controversy.

There have been patients identified with mild to moderate iron overload that are compound heterozygotes (C282Y/H63D) (47) or H63D homozygotes (48). It is rare for these cases to

\section{REFERENCES}

1. Adams PC, Reboussin DM, Barton JC, et al. Hemochromatosis and iron-overload screening in a racially diverse population. N Engl J Med 2005;352:1769-78.

2. Beutler E, Felitti V, Koziol J, Ho N, Gelbart T. Penetrance of 845G-> A (C282Y) HFE hereditary haemochromatosis mutation in the USA. Lancet 2002;359:211-8.

3. Asberg A, Hveem K, Kruger O, Bjerve K. Persons with screening-detected haemochromatosis: As healthy as the general population? Scand J Gastroenterol 2002;37:719-24.

4. Feder JN, Gnirke A, Thomas W, et al. A novel MHC class I-like gene is mutated in patients with hereditary hemochromatosis. Nat Genet 1996;13:399-408. have organ damage without another concomitant risk factor. Most persons with these genetic patterns have normal iron studies (1), and iron overload from a variety of causes can occur in patients with a normal or wild-type genotype.

\section{Target populations for screening}

A number of large studies have been done to further define the target populations for screening for iron overload. At the present time, it appears that men of northern European ancestry are the highest risk group for HFE-related hemochromatosis with iron overload. The HEIRS study (27) of 101,168 participants has demonstrated the low prevalence of HFE mutations in other ethnic populations. However, the HEIRS study demonstrated that North American persons of Asian (mostly Chinese and Vietnamese) descent have a higher prevalence of TS and ferritin elevations (1). AfricanAmerican iron overload has been reported, but population studies to date have not identified patients or pedigrees with this condition (49). Economic models that included genetic testing have suggested that screening for hemochromatosis would be effective even if only $20 \%$ of patients developed lifethreatening complications (7). Even this estimate may be high, and the natural history in the unscreened and untreated group remains poorly defined. There has been concern expressed about the negative effects of genetic testing, including genetic discrimination. Several studies have addressed this issue and have not demonstrated adverse psychosocial effects or genetic discrimination (50-54). A large screening study from Melbourne, Australia, demonstrated a high acceptance of genetic testing as the initial screening test (55). It seems that widespread population screening for hemochromatosis is unlikely to be recommended in North America (29), but more selected screening in high-risk populations requires further study.

\section{SUMMARY}

The present review attempts to provide the evidence-based data to support the first two important objectives of management of $\mathrm{HH}$, namely, early detection of the condition to prevent the development of organ damage with associated morbidity and, ultimately, increased mortality. The further discussion of management in terms of treatment and the monitoring of detected complications is outside the scope of the present paper. At this stage, the patient is usually referred for subspecialty supervision by hematologists or hepatologists.

ACKNOWLEDGEMENTS: The authors dedicate this manuscript to the late Dr David Brandhagen (Mayo Clinic, Rochester, Minnesota, USA) with whom we both shared many interesting discussions on the topic of hemochromatosis.

5. O'Neil J, Powell LW. Clinical aspects of hemochromatosis. Semin Liver Dis 2005;25:381-91.

6. Olynyk J, Cullen D, Aquilia S, Rossi E, Summerville L, Powell LW. A population-based study of the clinical expression of the hemochromatosis gene. N Engl J Med 1999;341:718-24.

7. Adams PC, Valberg LS. Screening blood donors for hereditary hemochromatosis: Decision analysis model comparing genotyping to phenotyping. Am J Gastroenterol 1999;94:1593-600.

8. Phatak PD, Guzman G, Woll JE, Robeson A, Phelps CE. Cost-effectiveness of screening for hereditary hemochromatosis. Arch Intern Med 1994;154:769-76. 
9. DuBois S, Kowdley K. Targeted screening for hereditary haemochromatosis in high-risk groups. Aliment Pharmacol Ther 2004;20:1-14

10. Pietrangelo A. Hereditary hemochromatosis: A new look at an old disease. N Engl J Med 2004;350:2383-97.

11. Pietrangelo A. Non-HFE hemochromatosis. Semin Liver Dis 2005;25:450-60.

12. Tavill AS. Diagnosis and management of hemochromatosis. Hepatology 2001;33:1321-8.

13. Sheldon JH. Haemochromatosis. London: Oxford University Press, 1935:164-340.

14. Edwards CQ, Cartwright GE, Skolnick MH, Amos DB. Homozygosity for hemochromatosis: Clinical manifestations. Ann Intern Med 1980;93:519-25.

15. Niederau C, Fischer R, Purschel A, Stremmel W, Haussinger D, Strohmeyer G. Long-term survival in patients with hereditary hemochromatosis. Gastroenterology 1996;110:1107-19.

16. Adams PC, Speechley M, Kertesz AE. Long-term survival analysis in hereditary hemochromatosis. Gastroenterology 1991;101:368-72.

17. Wojcik J, Speechley M, Kertesz A, Chakrabarti S, Adams P. Natural history of $\mathrm{C} 282 \mathrm{Y}$ homozygotes for hemochromatosis. Can J Gastroenterol 2002;16:297-302.

18. Adams PC. Hepatocellular carcinoma in hereditary hemochromatosis. Can J Gastroenterol 1993;7:37-41.

19. Asberg A, Hveem K, Thorstensen K, et al. Screening for hemochromatosis - High prevalence and low morbidity in an unselected population of 65,238 persons. Scand J Gastroenterol 2001;36:1108-15.

20. Ombiga J, Adams LA, Tang K, Trinder D, Olynyk JK. Screening for HFE and iron overload. Semin Liver Dis 2005;25:402-10.

21. Fletcher LM, Dixon JL, Purdie DM, Powell LW, Crawford DH. Excess alcohol greatly increases the prevalence of cirrhosis in hereditary hemochromatosis. Gastroenterology 2002;122:281-9.

22. Diwakaran HH, Befeler AS, Britton RS, Brunt EM, Bacon BR. Accelerated hepatic fibrosis in patients with combined hereditary hemochromatosis and chronic hepatitis C infection. J Hepatol 2002;36:687-91.

23. Adams PC, Bradley C, Henderson AR. Evaluation of the hepatic iron index as a diagnostic criterion in hereditary hemochromatosis. J Lab Clin Med 1997;130:509-14.

24. Crawford D, Jazwinska E, Cullen L, Powell LW. Expression of HLA-linked hemochromatosis in subjects homozygous or heterozygous for the C282Y mutation. Gastroenterology 1998;114:1003-8.

25. Bassett ML, Halliday JW, Powell LW. Value of hepatic iron measurements in early hemochromatosis and determination of the critical iron level associated with fibrosis. Hepatology 1986;6:24-9.

26. Summers KM, Halliday JW, Powell LW. Identification of homozygous hemochromatosis subjects by measurement of hepatic iron index. Hepatology 1990;12:20-5.

27. Adams PC, Reboussin DM, Leiendecker-Foster C, et al. Comparison of the unsaturated iron binding capacity with transferrin saturation as a screening test to detect $\mathrm{C} 282 \mathrm{Y}$ homozygotes for hemochromatosis in 101,168 participants in the HEIRS study. Clin Chem 2005;51:1048-52.

28. Bassett ML, Halliday JW, Ferris RA, Powell LW. Diagnosis of hemochromatosis in young subjects: Predictive accuracy of biochemical screening tests. Gastroenterology 1984;87:628-33.

29. Schmitt B, Golub R, Green R. Screening primary care patients for hereditary hemochromatosis with transferrin saturation and serum ferritin level: Systematic review for the American College of Physicians. Ann Intern Med 2005;143:522-36.

30. Edwards CQ, Griffen LM, Goldgar D, Drummond C, Skolnick MH, Kushner JP. Prevalence of hemochromatosis among 11,065 presumably healthy blood donors. N Engl J Med 1988;318:1355-62.

31. McLaren CE, McLachlan GJ, Halliday JW, et al. Distribution of transferrin saturation in an Australian population: Relevance to early diagnosis of hemochromatosis. Gastroenterology 1998;114:543-9.

32. Adams PC. Non-expressing C282Y homozygotes for hemochromatosis: Minority or majority of cases? Mol Genet Metab 2000;71:81-6.

33. Brissot $\mathrm{P}$, Bourel M, Herry D, et al. Assessment of liver iron content in 271 patients: A reevaluation of direct and indirect methods. Gastroenterology 1981;80:557-65.
34. Guyader D, Jacquelinet C, Moirand R, et al. Noninvasive prediction of fibrosis in C282Y homozygous hemochromatosis. Gastroenterology 1998;115:929-36.

35. Beaton M, Guyader D, Deugnier Y, Moirand R, Chakrabarti S, Adams P. Noninvasive prediction of cirrhosis in C282Y-linked hemochromatosis. Hepatology 2002;36:673-8.

36. Morrison ED, Brandhagen DJ, Phatak PD, et al. Serum ferritin levels predicts advanced hepatic fibrosis among U.S. patients with phenotypic hemochromatosis. Ann Intern Med 2003;138:627-33.

37. Bacon B, Powell LW, Adams PC, Kresina T, Hoofnagle JH. Molecular medicine and hemochromatosis: At the crossroads. Gastroenterology 1999;116:193-207.

38. Zoller H, Cox T. Hemochromatosis: Genetic testing and clinical practice. Clin Gastroenterol Hepatol 2005;3:945-58.

39. Adams PC. Implications of genotyping of spouses to limit investigation of children in genetic hemochromatosis. Clin Genet 1998;53:176-8.

40. Adams PC, Chakrabarti S. Genotypic/phenotypic correlations in genetic hemochromatosis: Evolution of diagnostic criteria. Gastroenterology 1998;114:319-23.

41. Yamashita C, Adams PC. Natural history of the C282Y homozygote of the hemochromatosis gene (HFE) with a normal serum ferritin level. Clin Gastroenterol Hepatol 2003;1:388-91.

42. Olynyk JK, Hagan SE, Cullen DJ, Beilby J, Whittall DE. Evolution of untreated hereditary hemochromatosis in the Busselton population: A 17-year study. Mayo Clin Proc 2004;79:309-13.

43. Andersen R, Tybjaerg-Hansen A, Appleyard M, Birgens H, Nordestgaard B. Hemochromatosis mutations in the general population: Iron overload progression rate. Blood 2004;103:2914-9.

44. Hanson E, Imperatore G, Burke W. HFE gene and hereditary hemochromatosis. Am J Epidemiol 2001;154:193-206.

45. Adams PC, Passmore L, Chakrabarti S, et al. Liver diseases in participants with an elevated transferrin saturation and ferritin in the Hemochromatosis and Iron Overload Screening Study. Clin Gastroenterol Hepatol 2006;4:918-23.

46. Cadet E, Capron D, Gallet M, et al. Reverse cascade screening of newborns for hereditary haemochromatosis: A model for other late onset diseases? J Med Genet 2005;42:390-5.

47. Bacon BR, Olynyk JK, Brunt EM, Britton RS, Wolff RK. HFE genotype in patients with hemochromatosis and other liver diseases. Ann Intern Med 1999;130:953-62.

48. Aguilar-Martinez P, Bismuth M, Picot M, et al. Variable phenotypic presentation of iron overload in H63D homozygotes: Are gene modifiers the cause? Gut 2001;6:836-42.

49. Barton JC, Acton RT, Rivers CA, et al. Genotypic and phenotypic heterogeneity of African Americans with primary iron overload. Blood Cells Mol Dis 2003;31:310-9.

50. Power T, Adams PC. Psychosocial impact of genetic screening for hemochromatosis in population screening and referred patients. Genet Test 2001;5:107-10.

51. Stuhrmann M, Hoy L, Schmidtke J. Genotype-based screening for hereditary hemochromatosis: Attitudes toward genetic testing and psychosocial impact - A report from a German pilot study. Genet Test 2005;9:242-54.

52. Patch C, Roderick P, Rosenberg W. Comparison of genotypic and phenotypic strategies for population screening in hemochromatoisis: Assessment of anxiety, depression and perception of health. Genet Med 2005; 7:550-6.

53. Anderson RT, Press N, Tucker DC, et al. Patient acceptability of genotypic testing for hemochromatosis in primary care. Genet Med 2005;7:557-63.

54. Hall MA, McEwen JE, Barton JC, et al. Concerns in a primary care population about genetic discrimination by insurers. Genet Med 2005;7:311-6

55. Delatycki MB, Allen KJ, Nisselle AE, et al. Use of community genetic screening to prevent HFE-associated hereditary haemochromatosis. Lancet 2005;366:314-6.

56. Burt MJ, George PM, Upton JD, et al. The significance of haemochromatosis gene mutations in the general population: Implications for screening. Gut 1998;43:830-6.

57. Hover AR, McDonnell SM, Burke W. Changing the clinical management of hereditary hemochromatosis: Translating screening and early case detection strategies into clinical practice. Arch Intern Med 2004;164:957-61. 


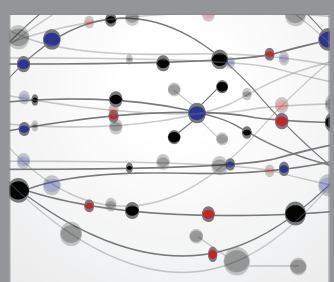

The Scientific World Journal
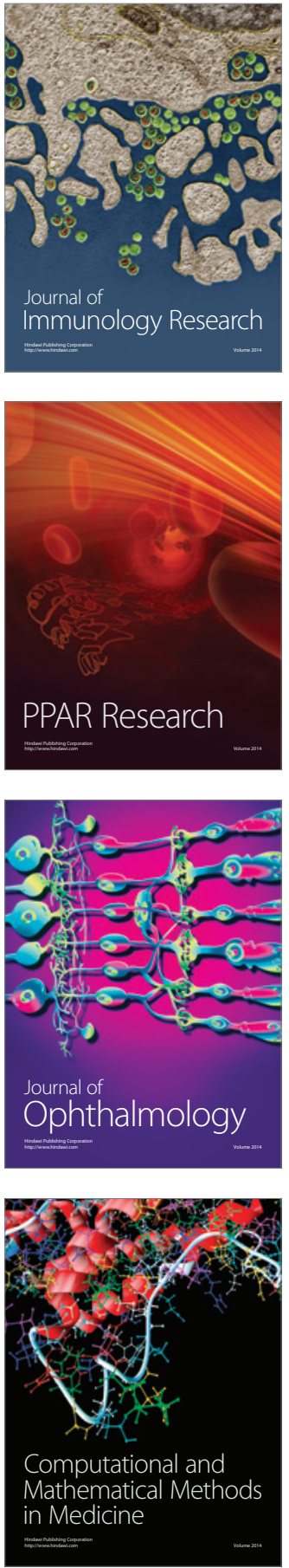

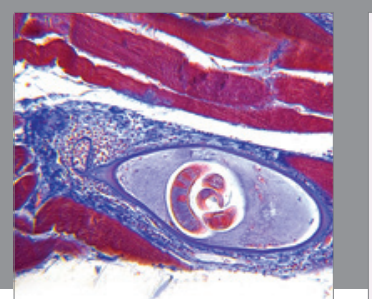

Gastroenterology Research and Practice

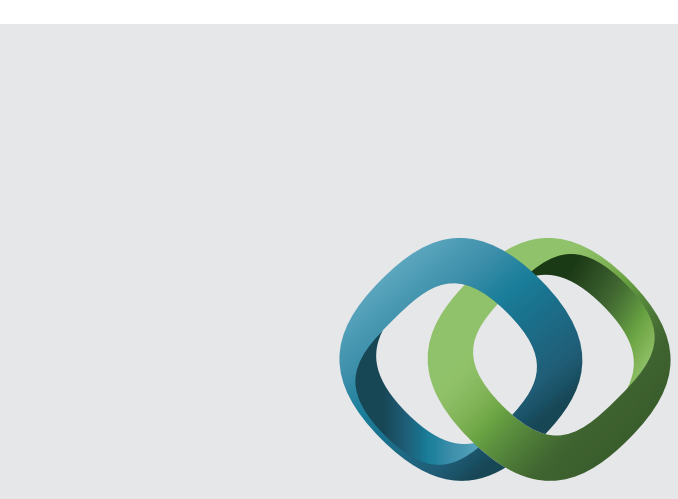

\section{Hindawi}

Submit your manuscripts at

http://www.hindawi.com
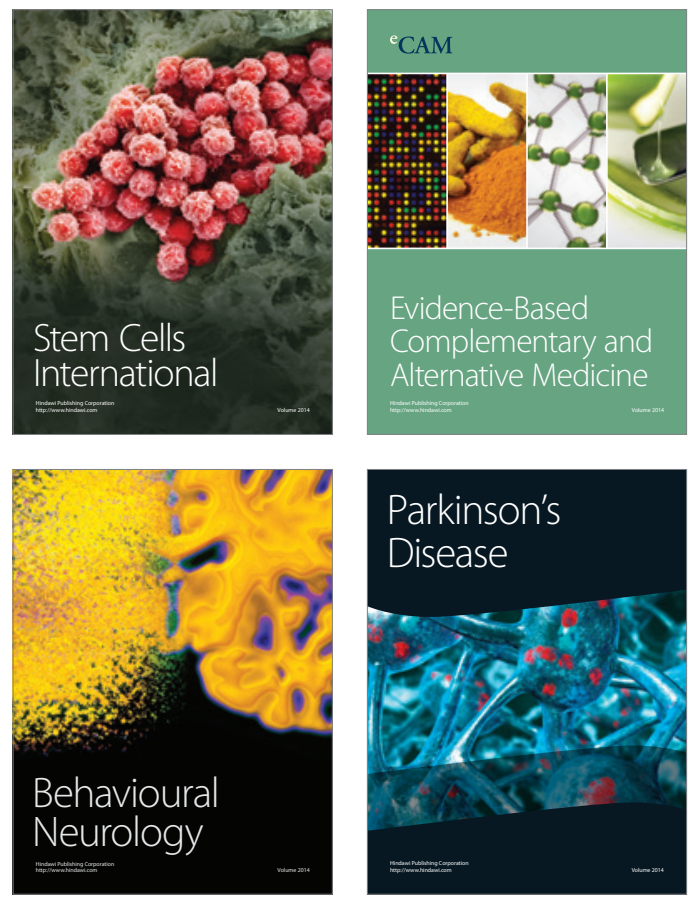
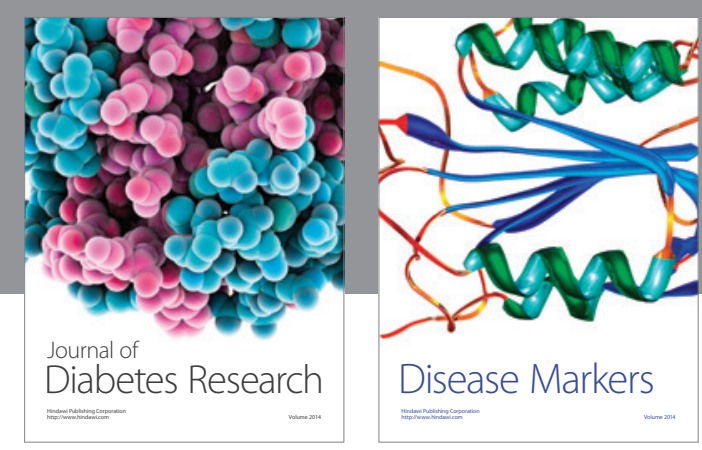

Disease Markers
